\title{
Program Surveillance after Breast Cancer Treatment: Contra
}

\author{
Jennifer J. Griggs Daniel F. Hayes \\ Breast Oncology Program, University of Michigan Comprehensive Cancer Center, Ann Arbor, MI, USA
}

Surveillance recommendations for patients with breast cancer following treatment of primary breast cancer include a periodic history and physical examination and annual mammography. Annual pelvic examinations are recommended for patients on tamoxifen. In addition, patients should be informed of symptoms that may indicate recurrence, and symptoms suggestive of possible recurrence should be promptly evaluated with appropriate imaging studies and blood tests [1]. European, Australian, Canadian, and United States guidelines groups have concluded that surveillance images - chest radiographs, nuclear medicine bone scans, and computerized tomography scans - are not warranted based on the findings of two randomized controlled trials conducted nearly 20 years ago $[2,3]$. The recently updated guidelines of the American Society of Clinical Oncology similarly advise against positron emission tomography (PET) scans as there are no data supporting the use of this imaging modality in the asymptomatic patient [1]. Serial ultrasound of the endometrium with vaginal ultrasound in patients on tamoxifen is also not supported in the literature [4]. Concordance with these guidelines is associated with reduced costs of care [5] and reduced cancer-related concern [6].

First, what would be the goal of doing so [7]? One would argue that early detection and therapy of asymptomatic metastases should result in one of three outcomes: possibility of cure, prolongation of survival, or improved palliation. Few, if any, patients with metastatic disease are cured, and there is little evidence that a few months lead time would change that statement. The randomized Italian trials, albeit performed with older technologies and less effective therapies than are now available, failed to demonstrate any survival benefit for treatment of asymptomatic metastases. Since by definition these patients are asymptomatic, they have no symptoms to palliate, unless one proposes that delay of symptoms outweighs the toxicities of therapy and the anxiety related to in- forming the patient that she has metastases. Second, false positive results from imaging studies will require biopsy, or repeated or additional imaging studies. These subsequent tests are, in turn, associated with patient anxiety, possible complications and costs. Although it is difficult to tease these data out, it is estimated that up to $50 \%$ of abnormal screening tumor marker and imaging study results will be falsely positive. Finally, negative screening results are often purported to reassure a patient. However, at any time point in a patient's course, in the absence of symptoms or physical findings, the odds of having a truly positive scan are less than $1-3 \%$, even in patients with a relatively high risk of recurrence, such as those with positive axillary lymph nodes in the second through fifth year of follow-up. Thus, absence of disease on imaging studies does not indicate that disease is not present or will not be present in the future.

Despite guidelines that do not support the use of surveillance imaging, many patients do undergo bone scans, abdominal and chest imaging, and chest radiographs. For example, in a study of women age 65 and older who were diagnosed between 1992 and 1999, in the Surveillance, Epidemiology, and End Results-Medicare database, $58.8 \%$ had a chest radiograph, $10.9 \%$ had abdominal and/or chest imaging, and $13.3 \%$ had a bone scan. Rates of appropriate mammography, although increasing, vary according to non-clinical factors such as race, geography, and marital status [8].

If there is no evidence of survival or quality of life benefit of surveillance imaging in the asymptomatic patient, why are physicians ordering such tests? We suspect that physicians are aware of consensus guidelines but believe that patients want to have regular surveillance imaging. Asymptomatic patients may inquire about the value of imaging studies in hopes of confirming that they are free of distant metastases. Applying the same message they have heard about detection of primary breast cancer, that early detection can lead to cure, patients

\begin{tabular}{ll}
\hline KARGER & ○ 2007 S. Karger GmbH, Freiburg \\
$\begin{array}{l}\text { Fax +497614520714 } \\
\begin{array}{l}\text { E-mail Information@Karger.de } \\
\text { www.karger.com }\end{array}\end{array}$ & $\begin{array}{c}\text { Accessible online at: } \\
\text { www.karger.com/brc }\end{array}$ \\
&
\end{tabular}

Jennifer J. Griggs, MD, MPH Breast Oncology Program University of Michigan Comprehensive Cancer Center 6312 Cancer Center, 1500 E. Medical Center Drive, Ann Arbor MI 48109-0942, USA Tel. +1734 647-9912, Fax -7672

E-mail jengrigg@umich.edu 
may be under the impression that earlier detection of metastatic disease is associated with a higher likelihood of cure [9]. In many ways, ordering imaging studies may seem less likely to cause distress than explaining that metastatic disease cannot be cured in the vast majority of patients.

Patients can, however, be effectively and compassionately be informed about the lack of benefit of non-breast surveillance imaging [10]. Patients are better served when their care providers treat them with high quality adjuvant therapy, obtain regular surveillance mammography, elicit and address concerns about recurrence, take a thorough history, and perform a complete physical examination. In addition, addressing barriers to adherence to hormonal therapy and managing long-term effects of cancer treatment are more likely to im- prove both survival and quality of life than obtaining surveillance imaging in the asymptomatic patient.

We acknowledge that newer serologic marker and imaging technologies might increase the accuracy of screening asymptomatic women for metastases, but no data support that claim. We also acknowledge that the development of better tolerated treatments, such as multiple endocrine therapies, more tolerable and active chemotherapeutic regimens, and more recently treatments targeted to HER-2 might offer opportunities to change the current dogma. We maintain, however, that before such changes in the currently accepted paradigm are made, well done clinical trials are needed to establish their benefit. Although such trials may be difficult to design and conduct, we would be highly supportive of these efforts.

\section{References}

1 Khatcheressian JL, Wolff AC, Smith TJ, Grunfeld E, Muss HB, Vogel VG, Halberg F, Somerfield MR, Davidson NE: American society of clinical oncology 2006 update of the breast cancer follow-up and management guidelines in the adjuvant setting. J Clin Oncol 2006;24:5091-5097.

2 Impact of follow-up testing on survival and healthrelated quality of life in breast cancer patients. A multicenter randomized controlled trial. The GIVIO Iinvestigators. JAMA 1994;271:1587-1592.

3 Rosselli DT, Palli D, Cariddi A, Ciatto S, Pacini P, Distante V: Intensive diagnostic follow-up after treatment of primary breast cancer. A randomized trial. National research council project on breast cancer follow-up. JAMA 1994;271:1593-1597.
4 Gerber B, Krause A, Muller H, Reimer T, Kulz T, Makovitzky J, Kundt G, Friese K: Effects of adjuvant tamoxifen on the endometrium in postmenopausal women with breast cancer: A prospective long-term study using transvaginal ultrasound. J Clin Oncol 2000;18:3464-3470.

5 Mille D, Roy T, Carrere MO, Ray I, Ferdjaoui N, Spath HM, Chauvin F, Philip T: Economic impact of harmonizing medical practices: Compliance with clinical practice guidelines in the follow-up of breast cancer in a french comprehensive cancer center. J Clin Oncol 2000;18:1718-1724.

6 Lash TL, Clough-Gorr K, Silliman RA: Reduced rates of cancer-related worries and mortality associated with guideline surveillance after breast cancer therapy. Breast Cancer Res Treat 2005;89:61-67.
7 Ellis M, Hayes DF, Lippman ME: Treatment of metastatic breast cancer; in Harris JLM, Morrow M, Osborne CK (eds): Diseases of the Breast. Philadelphia, Lippincott Williams and Wilkins, 2004, pp 1101-1062.

8 Keating NL, Landrum MB, Guadagnoli E, Winer EP, Ayanian JZ: Factors related to underuse of surveillance mammography among breast cancer survivors. J Clin Oncol 2006;24:85-94.

9 Muss HB, Tell GS, Case LD, Robertson P, Atwell BM: Perceptions of follow-up care in women with breast cancer. Am J Clin Oncol 1991;14:55-59.

10 Loprinzi CL, Hayes D, Smith T: Doc, shouldn't we be getting some tests? J Clin Oncol 2003;21: 108s-111s. 